\title{
Are we Prepared Enough? A Case Study Of Challenges In Online Learning In A Private Higher Learning Institution During The Covid-19 Outbreaks
}

\author{
Bibi Noraini Mohd Yusuf \\ Islamic University College, Perlis \\ Jihan Ahmad \\ Islamic University College, Perlis
}

\begin{abstract}
Online learning is a learning methodology implemented during the recent COVID-19 outbreaks. Lecturers and students need to use appropriate online platformsarising from the Movement Control Order (MCO) restrictions with effect from March 18, 2020, in Malaysia. In essence, the MCO prohibits Malaysians from attending to or organizing mass events or public gatherings, and where public and private educational institutions are concerned, they are not allowed to conduct any classesin situ. The only possible continuation of classes is via online learning. This case study had two research objectives: 1) Whatwere the challenges faced by educators when implementing online learning? and
\end{abstract} 2) How to overcome these challenges faced by educators in online learning? This study had applied the qualitative approach method, where researchers had distributed surveys, through a google platform, to a total of 20 educators. The results showed six (6) major challenges faced by educators in online learning, these being 1) students were less focused on online learning; 2) the platform/medium of learning was not satisfactory; 3) students left behind learning tools such as books and laptops in residential colleges; 4) students' internet access was less satisfactory to the extent that the lectures had to be extended from the actual time allocated; 5) educators' unstable internet access which disrupted the momentum of teaching; and 6) students did not attend the online courses. There were four (4) means to overcome these challenges 1) institutions to provide more comprehensive and e-learning platforms for online learning; 2) internet access for educators and students should be good to ensure smooth and uninterrupted online classes; 3) providing workshops or training programs on management of online classes for educators; and 4) for courses involving mathematical computation, in addition to a more suitable platform for teaching, the student population per group to be small in size to accommodate 10 educators while teaching. The results of this study shall benefit the management of private higher learning institutions and educators involved in online learning.

Keywords: Challenges in Online Learning, E-Learning and COVID-19 Outbreaks 
Yusuf, B. N. M., \& Ahmad, J. (2020) Are we Prepared Enough? A Case Study Of Challenges In Online Learning In A Private Higher Learning Institution During The Covid-19 Outbreaks. Advances in Social Sciences Research Journal, 7(5) 205-212.

\section{INTRODUCTION}

The first-ever documented case of a Covid-19 outbreak in Malaysia was reported on January 25, 2020, when a Chinese tourist, entering the country via Singapore, was found to be positively infectedwith the virus (being Malaysia's first confirmed case of the Covid-19 infection in 2020). According to official data released by the Ministry of Health Malaysia (MOH), as of April 14, 2020, there were 4,987 confirmed Covid-19 cases involving a total of 82 deaths. Figure 1 below depicts the latest statistics of Covid-19 cases in Malaysia.

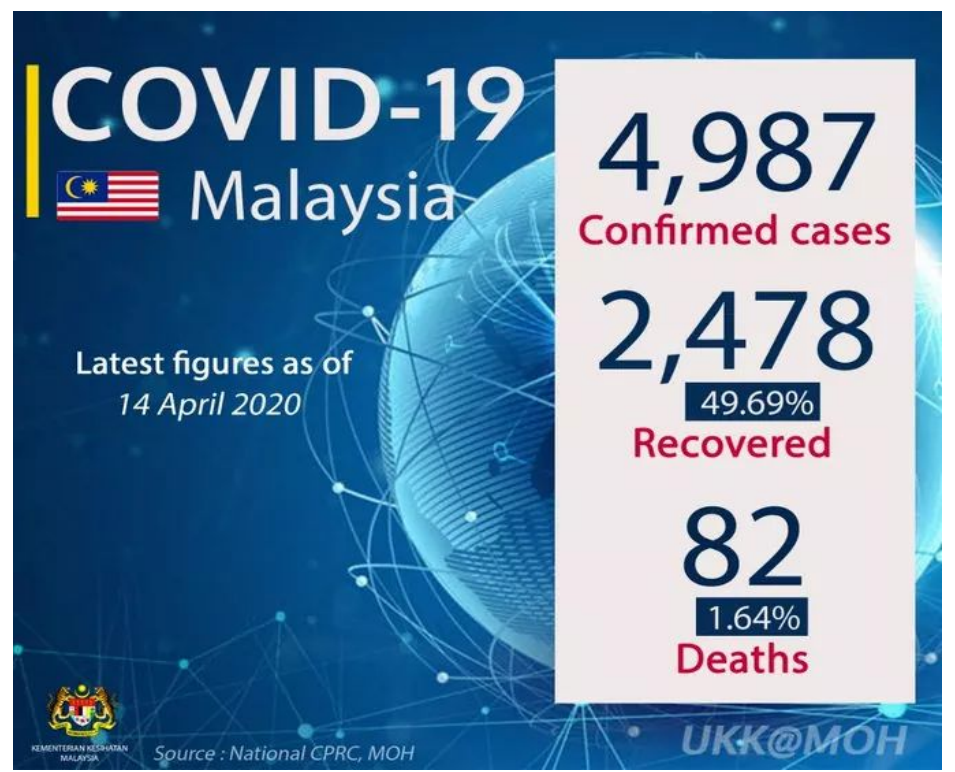

Figure 1: Number of Covid-19 Casesin Malaysia as of April 14, 2020

Source: MOH Facebook page, 14 April 2020.

Arising from the exponential daily increased in the number of Covid-19 infected cases, Malaysian Prime Minister, Tan Sri Muhyiddin Yassin has announced a phase-to-phase restricted movement order for Malaysians, known as the Movement Control Order (MCO) with came into effect from March 18, 2020 [18]. DuringPhase 1 of the MCO, amongst others, all public and private institutions of higher learning were required to postpone all classes and lectures for an initial period of two (2) weeks. Instead, these institutions were required to pursue classes and learning using any suitable online platforms beginning in April 2020. Henceforth, for the first time, all educators had to conduct courses and classeson an online basis. Invariably, this methodology has led to many challenges that educators faced when conducting these online classes. Due to this unprecedented phenomenon, researchers have found that there is a need forspecial research to be conducted based on the experiences that these educators had acquired. Outcomes of this research finding could be shared with interested parties and educators to understand the various challenges facing online learning methodology in the education fraternity in Malaysia and how to overcome these challenges.

Online education is the top choice methodology for educators after the MCO was extended in Phase 3 . The affected universities and institutions of higher learning, both public and private, had to look for the best alternative to ensure that teaching and coaching could continueuninterrupted, and online learning was the only route found suitable. Several crucial factors in implementing online learning also needed to be taken into consideration by management of these institutions, such as internet accessibility, speed, and time constraints faced by both educators and students. Online 
learning means teaching and having learning sessions conducted using technology and internet facilities. In other words, online learning involves web design and optimization, where all teaching materials are transferred and provided to students on an online basis (Kisanjara, 2020) [10]. There are three main theories in online learning methodologies, namely learning theory, optimization theory, and game theory (Hoi, Sahuu, Lu, and Zhaou, 2018) [7]. Based on their researches also Hoi, Sahuu, Lu, and Zhaou, (2018) [7], stated 3 categories of online learning groups, namely supervised online learning, online learning with limited feedback, and unsupervised online learning. Since online learning must be applied $100 \%$ or completely by educators during the Covid-19 outbreak (to minimize student movement), coupled with being first time undertaken by new educators in applying the online learning methodology, researchers have found opportunities to explore the challenges educators faced in online teaching and learning methods. There are two (2) main objectives of this study, firstly to explore the challenges faced by educators when conducting online lectures and secondly, ways to overcome these challenges faced by educators in conducting online lectures.

\section{LITERATURE REVIEW}

Online learning refers to teaching and learning online, where educators and students teach and learn respectively using appropriate learning platforms (Gunasekaran et al., 2002; Kanuka and Anderson, 2007 and Sun et al. 2008) [6; 8 \& 17]. The usual face-to-face lectures were not allowed in strict compliance with the MCO that the government has announced. Nowadays, learning through online is not only applied by public and private institutions, but also by the corporate sectors offering selected online courses. According to past research Agrawal et al. (2016) [1], there is six (6) significance of online methodology, including learners able to obtain expert knowledge, competitive and academic examination preparation, any-time and any-where access facility, interactive section, reduce the learning time, employability skills, sources of skills and knowledge maintained to procure data and personal interest. However, the online learning methodology conducted during the MCO was unprecedented and unplanned, where both parties, educators and students, were forced to adopt this teaching and learning method to continue learning for the remaining semesters. In institutions where the educators and students were familiar with this method prior to the MCO restriction, such learning and teaching process did not create any unnecessary problems. Nonetheless, for those who were first-timers and had to apply $100 \%$ online teaching and learning methods, there were certain challenges that they faced. These are the objectives that researchers are exploring.

According to past researchers, online teaching connects educators and students through electronic systems such as the internet, satellite, TV, CD-ROM, and Radio, etc for remote interactions between them. In order to accelerate the teaching and learning processes, educators and students must first comprehend the existing learning platforms. The present situation offers an advantage, as there is an existing social media platform where most students are familiar with the usage. So, in addition to other ancillary platforms developed by institutions of higher learning, such as Google Classroom, Moodle, and Webex, numerous existing social media platforms can also be used online, since students are also familiar with apps such as Whatsapp, Telegram, Facebook, Google Meet, and Instagram. Educators and students who are new or being first-timers in the process of understanding these online modes will surely face certain challenges. According to a study conducted by Ali, Uppal, and Gulliver (2017) [2], there are four (4) major barriers to online learning implementation, these being technology, individual, pedagogy and enabling conditions. Stacy, 
Yusuf, B. N. M., \& Ahmad, J. (2020) Are we Prepared Enough? A Case Study Of Challenges In Online Learning In A Private Higher Learning Institution During The Covid-19 Outbreaks. Advances in Social Sciences Research Journal, 7(5) 205-212.

Meredith, and Christian (2018) [16] in their study noted that one of the challenges for educators and students when it comes to online learning is interrupting oppressive language and behaviors.

Full implementation of online learning and teaching methodology in higher education institutions requires full commitment from educators and students. Those involved need to enhance their knowledge and readiness in this new teaching and learning process. In addition to the skills (enabling educators and students to use online platforms well), adequate internet facilities and online guidelines are also prerequisites to be made available so that learning can be implemented smoothly. According to Munezero, Irura, Kirongo, Etiegni and Suhonen (2016) [13], there are six (6) major challenges for universities, educators and students when e-learning methodology is implemented - ICT infrastructure, online skills needed, the security of platform used, university support, motivation to lecturers and students while using the online method, and context-specific. The main question to be explored is whether we are prepared enough in implementing successful virtual classroom sessions during the Covid-19 phenomena.

\section{RESEARCH METHODOLOGY}

This study applied a qualitative research methodology. Qualitative research questions such as on "Why?" and "How?" for specific human behaviors are distinctly subjective, reflecting the individual's opinions, thoughts, and feelings. The qualitative method is ideal for understanding the behaviors, values, and perceptions of a particular culture, or exploring unfamiliar phenomena. As stated by Madrigal and McClain (2012) [11], qualitative studies can provide details about human behavior, emotion, and personality characteristics that quantitative studies cannot match. Researchers had conducted a short case study involving educators at the Faculty of Business and Management Sciences at one of the private institutions of study in the northern region of Malaysia. Questions developed were based on past research studies in this survey and were open-ended. According to Check and Schutt (2012) [3], surveys are conducted to collect participant's answers to the questions asked. Participants are asked to provide answers in the space provided (long paragraph). Survey methods are also used by researchers to describe and explore constructs of interest and variables. Researchers have developed a google-form and distributed it to participants through Whatsapp application. In analyzing the data (feedbacks) obtained, the researchers used thematic analysis.

Thematic analysis has historically been a common practice in qualitative research, involving searching through the data to identify recurrent themes or patterns. A theme is a cluster of linked categories conveying similar meanings and usually emerges through the inductive analytic process which characterizes the qualitative paradigm [15]. As the first step, the identification of suitable themes was made using both the thematic analysis and the general inductive reasoning. The most crucial consideration in identifying themes was that firstly, researchers must be systematic across the data and secondly, the coding of the texts must be done according to memos/themes. To ensure fairness and eliminate elements of biases, researchers should create themes based on the respondent's perspective, instead of relying solely on my own perspective. By doing so, researchers had paid tribute to each respondent's unique responses rather than steering them with selfdeveloped questionnaires and ultimately obtaining outcomes which incorrectly matched my own pre-conceived ideas. After identifying the different themes, researchers could work in a more condensed environment, where all features on keywords and concepts had been highlighted. These concepts were then organized, combined or clustered, and this process was repeated with other new sets of concepts until no new themes or concepts emerged. 


\section{FINDINGS}

A total of 20 faculty members (educators) had participated in the survey and all the participants in this study were first-timers conducting online classes fully (100\%). Out of the total participants, 13 participants (65\%) were female with the remaining 7 participants $(35 \%)$ being male. The participants involved in this survey came from 3 main departments, namelyBusiness, Accounting, and Information Technology. The total number of students in each participant's class ranged from 16 to 88 students. There were nine (9) major teaching and learning medium applications and platforms used by the educators in this institution, namely Zoom, Google Classroom, WhatsApp, Google Meet, Webex, Screen and Voice PowerPoint slides, Google Drive, Screen share recording, and lastly Telegram.

The results showed that the educators had applied two (2) teaching and learning approach methods, firstly synchronous teaching and learning, and secondly, asynchronous learning. In the first method (synchronous teaching and learning approach), educators and students met and communicated in a virtual classroom. Otherwise, for educators and students who did not have good internet access, they had applied the second (asynchronouslearning) method that allowededucators to upload videos and audio lectures and reading information to students and students who could study at a later or at any given time when the internet facilities were in stable conditions. There were also educators using both the synchronous and asynchronous methodssimultaneously. Overall, $60 \%$ of educators had internet problems whilst $40 \%$ of educators did not encounter any internet access problems. Educators who had applied the single synchronous and asynchronous methods in the learning process accounted for $10 \%$ and $5 \%$ respectively, whilst the bulk of $85 \%$ involved those educators who had applied a combination of both processes. It was highlighted out that one of the factors that had caused them to implement both teaching methods (a combination of synchronous and asynchronous) was due to poor/slow internet access. Thus, students with inferior or poor internet access could aptly attend lectures recorded by these educators.

In addressing the objectives of the first study (challenges faced by educators in the faculty), there were six (6) major findings observed:

1. Students were less focused on online teaching and learning;

2. Learning platform/medium was not satisfactory;

3. Students were without basic learning tools, such as books and laptops (which were left behind in their residential colleges);

4. Internet access was not satisfactory to the extent that lectures needed to be extended from the actual lecture period;

5. Poor internet access to educators causing disruption to learning time; and

6. Students did not attend the online lectures.

It was observed that there were six (6) reasons where students did not attend the sessions arranged as stated by educators in this study: sick leave/health problems, personal problems, no computer/laptop damaged, no direct feedback from students, no/poor internet access, and the uncomfortable/non-conducive home environment (not ideal for online learning).

In respect of the second objective (to overcome the challenges or obstacles faced by educators), the researcher found four (4) themes as suggested by the participants, namely; 
Yusuf, B. N. M., \& Ahmad, J. (2020) Are we Prepared Enough? A Case Study Of Challenges In Online Learning In A Private Higher Learning Institution During The Covid-19 Outbreaks. Advances in Social Sciences Research Journal, 7(5) 205-212.

1. Institutions need to provide more comprehensive and e-learning platforms for online learning;

2. Access to the internet for both educators and students should be good to ensure smooth and uninterrupted online learning process;

3. Provide workshops or training facilities on online classroom management to educators; and

4. For courses involving mathematical computation, in addition to more suitable platforms for teaching, the student population for each group should also be small in size (say 10 students) to facilitate teaching by the educators during the sessions.

A total of 13 educators (65\%) said they needed training in conducting online teaching and 7 others (35\%) said they did not need training in this aspect. Availability of online teaching training would help the educators to be fully prepared for this method of learning in the future.

\section{LIMITATIONS AND FUTURE RESEARCH}

This study was limited to 20 educators from only one faculty at a private institution of higher learning located in the northern region of Malaysia. Data obtained from these 20 participants could not be generalized to all institutions of higher learning throughout Malaysia. The data obtained were mainly preliminary data for the themes and factors for this specific research topic. In the future, other researchers will need to conduct an extensive quantitative study so that the data and statistics obtained can be expanded and generalized to all public and private institutions of higher learning in Malaysia. Researchers can also make a comparison of the results of studies between public and private institutions of higher learning in the future. In addition, this study only reviewed the scope ofstudy on challenges and how to overcome the challenges faced by online educators, and in the future, the scope of the study may be extended to the scope of institutions and incorporating feedback from the students involved in online learning as well.

\section{DISCUSSION AND CONCLUSION}

This study outcome can provide some insights to those involved in distance learning and teaching, especially institutions offering programs of study, educators, and students in online learning. In addition, this study may contribute to the development of learning methods in addition to direct face-to-face or classroom practices. The findings can also serve as guidance for educators in understanding the challenges of online teaching. Based on the findings of this study, the challenges listed above are that students are less focused on teaching and learning via online; platform/medium of learning has not been satisfactory; students leaving behind learning tools such as books and laptops in their residential colleges; students' internet access is less satisfactory to the extent that the lectures need to be extended from the actual lecture period; educators' unstable internet access leading to disruption of classes, and students do not attend the online course as scheduled. Kari and Owston (2016) [9] stated that amongst barriers encountered by online educators are the technical problemsrelating to the online system used, such as the absence of ALT text for images and hyperlinks. Gebremariam, Gheorghita, Tor-Morten, and Wu-Yuin (2018) [4] stated that in order to ensure that online learning runs well, experience among educators also needs to be good especially on the platforms and mediums used in online learning.

In addition, the use of technology and internet facilities among educators and students is also one of the barriers reported in the study by Gillet-Swan (2017) [5]. This constraint is a challenge because there are good educators who have greater skills and know-how on information technology 
and thus be able to use more advanced technology architectures, whereas students have limited knowledge of basic information technology architectures. Apart from that, Rana, Lal, and Rajiv (2014) [14] found four (4) key challenges in implementing virtual classroom teaching, these being technological challenges, development of new interactive learning and community challenges, developing a piece of new knowledge on e-learning facilities, and pedagogical issues on online learning. In a nutshell, institutions of higher learning need to play a bigger role in providing convenient platforms for teaching and learning online for both educators and students. In addition, the skills of using information technology by educators need to be enhanced to make the teaching process more seamless and interesting in the future.

\section{References}

[1] Agrawal, V., Agrawal, A. and Agrawal, S. (2016). Assessment of factors for e-learning: an empirical investigation. Industrial and Commercial Training.48(8), 2016, pp. 409-415

[2] Ali, S.; Uppal, M.A. and Gulliver S.R. (2017).A conceptual framework highlighting e-learning implementation barriers.Information Technology \& People Journal.31(1), 2018, pp 156-180.

[3] Check J., Schutt R. K. Survey research. In: J. Check, R. K. Schutt., editors. Research methods in education. Thousand Oaks, CA: Sage Publications; 2012. pp. 159-185.

[4] GebremariamMesfin, GheorghitaGhinea, Tor-Morten Grønli and Wu-Yuin Hwang.(2018). Journal of Educational Technology \& Society.21(4), Special Issue on "Authentic Edutainment with Advanced Technologies" (October 2018), pp. 157-170.

[5] Gillett-Swan, J. (2017). The Challenges of Online Learning Supporting and Engaging the Isolated Learner.Journal of Learning Design. Special Issue: Business Management. 10(1), pp. 20-30.

[6] Gunasekaran, A., McNeil, R.D. and Shaul, D. (2002).E-learning: research and applications. Industrial and Commercial Training, 34(2), pp. 44-53.

[7] Hoi, S.C.H., Sahoo, D., Lu, J. \&Zhaou, P. (2018). Online Learning: A Comprehensive Survey. SMU Technical Report 1 (2018), pp. 1 - 100.

[8] Kanuka, H. and Anderson, T. (2007).Ethical issues in qualitative e-learning research.International Journal of Qualitative Methods.6(2), pp. 1-14.

[9] Kari L. Kumar and Ron Owston Source: Universal Design for E-Learning Can Benefit All Students. Educational Technology Research and Development Journal.64(2) (April 2016), pp. 263-283.

[10] Kisanjara, S. (2020).Factors Influencing E-Learning Implementation In Tanzanian Universities.The Online Journal of Distance Education and e-Learning.January 2020,8(1). Pp. 37-54.

[11] Madrigal., D \& McClain., B. (2012). Strengths and weaknesses of quantitative and qualitative research. Retrieved from :http://www.uxmatters.com/mt/archives/2012/09/strengths-and-weaknesses-of-quantitative-and-qualitativeresearch.php

[12] Malaysia confirms first cases of coronavirus infection. (2020). Retrieved from:https://www.reuters.com/article/china-health-malaysia/malaysia-confirms-first-cases-of-coronavirusinfection-idUSL4N29U03A

[13] Munero, M.; Irura, M.; Kirongo, B.;Etiegni, L and Suhonen, J. (2016). Challenges And Solutions To Providing Online Courses In Kenya: A Lecturer's Perspective At A Kenyan University. The Online Journal of Distance Education and eLearning, January 2016. 4(1). Pp. 1-14.

[14] Rana, H. Rajiv and Lal, M. (2014). E-learning: Issues and Challenges. International Journal of Computer Applications. (0975 - 8887). 97(5), July 2014.

[15] Ryan, G.W., and Bernard, H.R. (2003).Techniques to Identify Themes.Retrieved from: http://journals.sagepub.com.doi/abs/10.1177/1525822X02239569. 
Yusuf, B. N. M., \& Ahmad, J. (2020) Are we Prepared Enough? A Case Study Of Challenges In Online Learning In A Private Higher Learning Institution During The Covid-19 Outbreaks. Advances in Social Sciences Research Journal, 7(5) 205-212.

[16] Staci B. Martin, Meredith E. Michaud and Christian D. Logerstedt Source: The Journal of General Education.67(34) (2018), pp. 251-268 Published by: Penn State University Press.

[17] Sun, P.C., Tsai, R.S., Finger, G., Chen, Y.Y. and Yeh, D. (2008).What drives a successful e-learning? An empirical investigation of the critical factors influencing learner satisfaction.Computers Education50(4), pp. 1183-202.

[18] Tang, Ashley. (2020). Malaysia Announces Movement Control Order After Spike in Covid 19 Cases (Updated).The Star, archived from the original on March 16, 2020. 